\title{
Onychocryptosis together with onychomycosis due to non dermatophyte molds treated by brace and citric acid
}

\author{
Erdogan F Gülru*, Yıldırım Dilsun, Gürbüz Özge and Dinçer Didiem \\ Department of Dermatology, Faculty of Medicine, Ufuk University, Turkey
}

\section{Introduction}

Onychomycosis is estimated to affect $10 \%$ of the population however, the incidence is belived to be gradually increasing. On the other hand, resistance to systemic and topical antifungals is also an emerging concern [1-3]. Causative fungi were majorly believed to be dermatophytes a few decades ago where non dermatophyte molds and yeasts are accepted to be contaminants and hence would not change treatment plan of patients [4]. However, recently, increasing number of studies show more cases of onychomycosis due to molds and yeasts [3-10].

Onychomycosis is also considered to be one of the causes of ingrown nails. However, patients with ingrown nails are mostly operated rather than explored for fungus; therefore most probably gradual thickening and colour changes due to fungal infections are mostly overlooked. On the other hand systemic antifungal treatment may also lead to ingrown nails [11].

Gradual thickening of the nail due to fungal infection from the distal end leading to over curvature and pain on nail sides is usually attempted to be treated by local and systemic antifungals e.g. terbinafine and itrokanozole. However, these treatment agents are sometimes ineffective. In other instances it may not be possible to use them as in case of pregnancy and nursing.

Sometimes patients accept the disfigurement as untreatable and search for help only for ingrown nail rather than thickening and color change.

Here we present a case of bilateral and ingrown nails seemed to be associated with non dermatophyte mold infection and benefited from nail brace and 5\% citric acid applications in weeks.

\section{Case}

Sixty nine year old female patient complained of bilateral painful ingrown nails with over curvature and thickening of nails for last four years. She used pedicures for pain relief with no permanent effect. She was told to have fungal infection on nails and had used various topical antifungal agents for nail thickening, without benefit.

We performed maldi-tof technique for the isolation of fungus and found out rhizopus type non dermatophyte mold on the nail plate.

We applied nail braces for onychocryptosis and the patient had immediate relief from pain, we also started 5\% citric acid in water solution application with the aid of a brush under the nail once or twice daily. She used both for six weeks with complete normalization of nail curve and thinning of nail plate.
Therefore we took off the brace and stopped citric acid application in six weeks.

One month after the cessation of treatment we repeated maldi tof and no fungus could be isolated this time.

On the follow up, patient had no recurrence 4 months after the cessation of treatment.

\section{Discussion}

Although systemic and topical antifungal agents are being widely prescribed, susceptibility tests can not routinely be carried out for them. Systemic antifungal treatment is discussed for not being practical or economical due to the fact that usually patients are checked for clinical improvement and liver function tests monthly at least for 3 months, and also have the risk of many drug interactions.

Besides the fact that more and more patients refuse taking systemic treatment for nail fungus infection, nor can they receive it during pregnancy or nursing.

Dermatophytes were believed to be the major causative agent for onychomycosis [4]. However nowadays there is increasing evidence saying non dermatophyte molds are even more prevalent than dermatophytes, one of the reasons of which may be wide use of systemic antifungal agents [3,5-7]. Besides, non dermatophyte molds are getting increasingly resistant to widely used topical and systemic antifungal treatment agents $[3,9,10,12]$.

Onychocryptosis has various etiologies. However, over curvature of the nail plate together with severe pain is usually considered to be an indication for operation. Although we apply braces for such patients, it usually takes at least 3-4 months for the nail curve to be normalized. Patients have pain relief immediately; however the shape and thickening of the nail remain the same for months. Even when the nail curve is finally normalised, thickening still remains.

Onychocryptosis as a result of fungal infections has limitations as one of the widely prescribed agents itself is reported to trigger ingrown nails. In our first case patient used 4 months of systemic terbinafine with topical ciclopirox however, she mentioned her complaints were getting even worse. Triggering of onychocryptosis after systemic terbinafine treatment may be due to overgrowth of treatment resistant non dermatophyte molds and hence lead to thickening and overcur-

Correspondence to: Erdogan F Gülru, Department of Dermatology, Faculty of Medicine, Ufuk University, Turkey, E-mail: gulruer@gmail.com

Received: April 25, 2016; Accepted: May 12, 2016; Published: May 16, 2016 


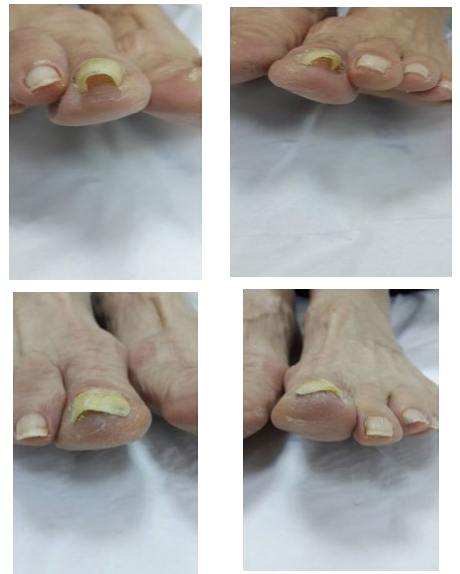

Figure 1. A Both toe nails before treatment, BSame toe nails 4 months after the cessation of treatment.

vature of nails as in our cases $[10,11]$.

Keratolytic agents may help for superficial fungal infections, however their role in helping nail braces for nail correction are new to us. Keratolytic agents may help correct pincer nails as well especially in patients with progressive thickening of the nail and with fungal infections.

Although in distal subungual onychomycosis cases like our cases, it may be hard to apply treating agent onto the nail bed, over curvature of the nails, in all of the patients here, enabled us apply citric acid properly under the nails and on the nail bed.

\section{References}

1. Klobucnikova V, Kohut P, Leber R, Fuchsbichler S, Schweighofer N, et al. (2003) Terbinafine resistance in a pleitropic yeast mutant is caused be a single point mutation in the ERG1 gene. Biochem\&Biophysic Research Commun309: 666-671. [Crossref]

2. Elewski BE (1998) Onychomycosis: pathogenesis, diagnosis, and management. ClinMicrobiol Rev 11: 415-429.[Crossref]

3. Tosti A, Piraccini BM, Lorenzi S (2000) Onychomycosis caused by nondermatophyticmolds: clinical features and response to treatment of 59 cases. $J \mathrm{Am}$ AcadDermatol 42: 217-224.[Crossref]

4. Ellis DH, Watson AB, Marley JE, Williams TG (1997) Non-dermatophytes in onychomycosis of the toenails. Br J Dermatol 136: 490-493.[Crossref]

5. HilmioÄŸlu-Polat S, Metin DY, Inci R, Dereli T, KilinÃ § I, et al. (2005) Nondermatophyticmolds as agents of onychomycosis in Izmir, Turkey - a prospective study. Mycopathologia 160: 125-128.[Crossref]

6. Ranawaka RR, de Silva N, Ragunathan RW (2012) Non-dermatophyte mold onychomycosis in Sri Lanka. Dermatol Online J 18: 7. [Crossref]

7. Maged El Batawi M, Arnaot H, Shoeib S, Bosseila M, El Fanfary M, et al. (2006) Precalence of Non dermatophytemolds in patients with abnormal nails. Egyptian Dermatology Online Journal 2: 1-12.

8. Malik NA, Raza N, Nasiruddin (2009) Non dermatophyte moulds and yeasts as causative agents in onychomycosis. J Pakistan AssocDermatol 19: 74-78.

9. Takahata Y, Hiruma M, Sugita T, Muto M (2008) A case of onychomycosis due to Aspergillussydowii diagnosed using DNA sequence analysis. Mycoses 51: 170-173. [Crossref]

10. Baudraz-Rosselet F, Ruffieux C, Lurati M, Bontems O, Monod M (2010) Onychomycosis insensitive to systemic terbinafine and azole treatments reveals non dermatophyte moulds as infectious agents. Dermatology 220: 164-168. [Crossref]

11. Weaver TD1, Jespersen DL (2000) Multiple onychocryptosis following treatment of onychomycosis with oral terbinafine. Cutis 66: 211-212.[Crossref]

12. Lurati M1, Baudraz-Rosselet F, Vernez M, Spring P, Bontems O, et al. (2011) Efficacious treatment of non-dermatophyte mould onychomycosis with topical amphotericin B. Dermatology 223: 289-292.[Crossref]

Copyright: $\odot 2016$ Gülru EF. This is an open-access article distributed under the terms of the Creative Commons Attribution License, which permits unrestricted use, distribution, and reproduction in any medium, provided the original author and source are credited. 